INFORMACION BIBLIOGRAFICA Y DOCLMENTAL.

\section{Conservación Arquitectónica}

Brancato, Francesco S. La prevenzione del degrado: propedeutica alle tecnologie del recupero edilizio. Palermo; Sao Paulo: ILA Palma, cop. 1991

Manutenzione e conservazione del costruito fra tradizione ed innovazione: Atti del convegno di Studi Bressanone 24-27 Giugno 1986. Padova: Libreria Progetto Editore, [198-]

Papel, libros y materiales de archivos y objetos

Conservazione delle opere d'arte, su carta e pergamena: atti del convegno, Torgiano, 14-16 aprile 1988. [S.1.]: Volumnia, [1990?]

Cerámica, vidrio y esmaltes

Buys, S., Oakley, V. The conservation and restoration of ceramics. London [etc.]: Butterworth-Heinemann, 1993

Piedra, minerales y materiales relativos a edificios

Adams, A.E., Mackenzie, W.S., Guilford, C. Atlas od sedimentary rocks under the microscope. Harlow: Longman Scientific \& Technical , 1994

Ricci, M., dir. Manutenzione e restauro: Conservazione e consolidamento dei materiali lapidei. Milano: Antonino Giuffrè, [19- ]

Técnicas de análisis

Bennett, $\mathrm{H}_{\text {., }}$ Oliver, Graham J. XRF Analysis of Ceramics, Minerals and Allied Materials. Chichester [etc.]: John Wiley \& Sons, 1992

Datation-caractérisation des céramiques anciennes: Bordeaux-Talence, 6-8 avril 1981: cours intensif européen organisé dans le cadre de programme intergouvernemental du Conseil de l'Europe dans le domaine de l'enseignement supérieur et de la recherche. París: CNRS; Ravello [Italia]: Centre Universitaire Européen pour les biens culturels, D.L. 1984

\section{DOCUMENTACION}

López Yepes, A. Documentación multimedia: el tratamiento automatizado de la información periodistica, audiovisual y publicitaria. Salamanca: Universidad Pontificia, 1993
López Yepes, A. Manual de documentación audiovisual. Pamplona: Universidad de Navara. 1992

\section{MUSEOLOGIA}

Museum Security and Protection: a handbook for cultural heritage institutions. London: ICOM: New York: Routledge, 1993

\section{PATRIMONIO HISTORICO}

Boniface, P., Fowler, P.J. Heritage and Tourism in the "global village". London; New York: Routledge, 1993

Heritage \& Tourism: ICOMOS European conference, Canterbury, University of Kent, 27th-30th march 1990. London: ICOMOS, [1990?]
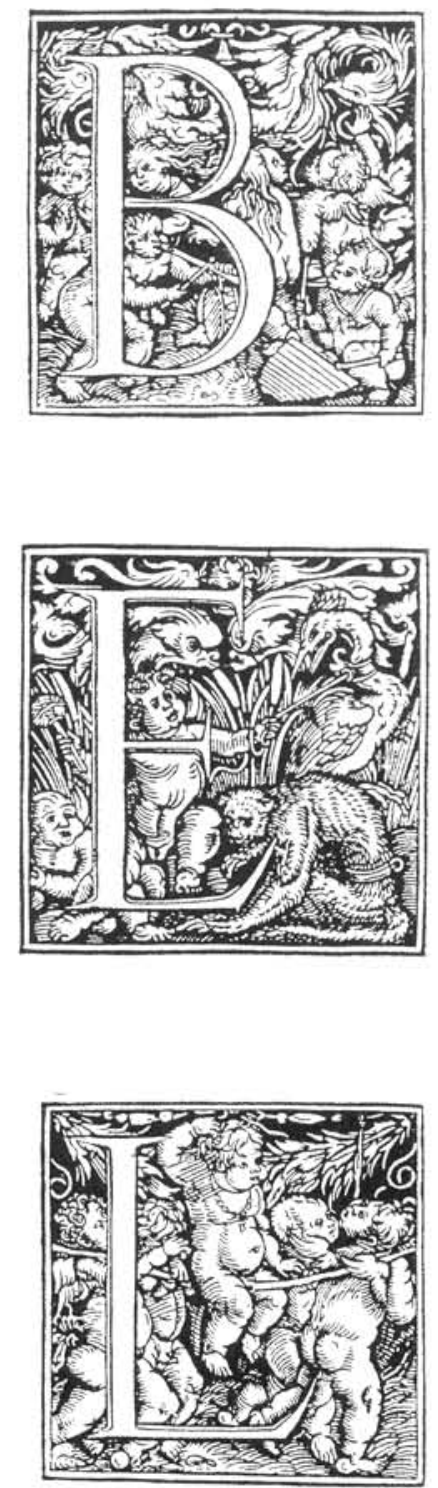

ICOM Committe for Conservation IOth Triennial meeting Washington, Dc, Usa 22-27 August 1993

Presentamos la publicación del último de los Congresos del ICOM, celebrado en Washington en agosto de 1993; en la publicación se incluyen tanto las comunicaciones como los trabajos presentados en la sección de posters.

El número de comunicaciones presentadas en este congreso es de 133, referidas a la temática de Conservación y Restauración. Dentro de este ámbito se concretan temas como: Análisis de Laboratorio, Arte Rupestre. Contaminación atmosférica, Cromatografía, Cuero, Formación Profesional, Humedad, Limpieza, Madera, Materiales Etnográficos, Papel, Pintura, Restos Arqueológicos, Soportes, Técnica, Tejidos.

EI ICOM ( International Council of Museums) es una organización no lucrativa cuyos objetivos son los de promover el desarrollo y la investigación en el ámbito de los museos. Incluye museos de diferentes materias como son los de historia, los etnológicos, los de objetos de arte, jardines botánicos, acuarios.

Su actuación se extiende por los cinco continentes, favoreciendo el intercambio de información entre los diferentes países y se asocia a la UNESCO en calidad de organización no gubernamental.

El ICOM está constitutido por un Secretario General y el Centro de Documentación que tiene su sede en París, 75 Comités Nacionales y 29 Comités Internacionales especializados, que se subdividen en diferentes subgrupos de trabajo. Todos estos Comités se reunen con una periodicidad predeterminada.

Dentro de los Comités Internacionales existe uno de Conservación, que a su vez está compuesto por 26 grupos como el análisis de las obras de arte, la enseñanza dentro del campo de la restauración y conservación artística, los documentos gráficos y los materiales etnográficos, la pintura sobre lienzo, etc.

Para más información acerca del este Congreso pueden dirigirse al Centro de Documentación del IAPH, tanto para obtener información acerca de los títulos de las comunicaciones, autores, materias, etc., como para la consulta de la publicación. 